\title{
Dynamic Tuning of Electrical and Chemical Synaptic Transmission in a Network of Motion Coding Retinal Neurons
}

\author{
Stuart Trenholm, ${ }^{1}$ Amanda J. McLaughlin, ${ }^{1}$ David J. Schwab, ${ }^{2}$ and Gautam B. Awatramani ${ }^{1}$ \\ ${ }^{1}$ Biology Department, University of Victoria, Victoria, British Columbia V8W 3N5, Canada, and 2Department of Physics, Princeton University, Princeton, \\ New Jersey 08544
}

Recently, we demonstrated that gap junction coupling in the population of superior coding ON-OFF directionally selective ganglion cells (DSGCs) genetically labeled in the Hb9::eGFP mouse retina allows the passage of lateral anticipatory signals that help track moving stimuli. Here, we examine the properties of gap junctions in the DSGC network, and address how interactions between electrical and chemical synapses and intrinsic membrane properties contribute to the dynamic tuning of lateral anticipatory signals. When DSGC subtypes coding all four cardinal directions were individually loaded with the gap junction-permeable tracer Neurobiotin, only superior coding DSGCs exhibited homologous coupling. Consistent with these anatomical findings, gap junction-dependent feedback spikelets were only observed in $\mathrm{Hb}^{+}{ }^{+}$DSGCs. Recordings from pairs of neighboring $\mathrm{Hb}^{+}$DSGCs revealed that coupling was reciprocal, noninactivating, and relatively weak, and provided a substrate for an extensive subthreshold excitatory receptive field around each cell. This subthreshold activity appeared to boost coincident light-driven chemical synaptic responses. However, during responses to moving stimuli, gap junction-mediated boosting appeared to be dynamically modulated such that upstream DSGCs primed downstream cells, but not vice versa, giving rise to highly skewed responses in individual cells. We show that the asymmetry in priming arises from a combination of spatially offset GABAergic inhibition and activity-dependent changes in intrinsic membrane properties of DSGCs. Thus, dynamic interactions between electrical and chemical synapses and intrinsic membrane properties allow the network of DSGCs to propagate anticipatory responses most effectively along their preferred direction without leading to runaway excitation.

\section{Introduction}

Similar to chemical synapses, electrical signals mediated by gap junctions are subject to activity-dependent regulation and plasticity (for review, see Pereda et al., 2013) that control signal spread through neural networks. Activity can either modify the properties of the gap junctions themselves (Zsiros and Maccaferri, 2008; Haas et al., 2011; Kothmann et al., 2012) or modulate the efficacy of electrical signaling indirectly through changes in membrane properties (Llinas et al., 1974; Mann-Metzer and Yarom, 1999; Curti et al., 2012; Trenholm et al., 2012). However, as most gap junction studies have used in vitro preparations where natural patterns of activity are not preserved, the dynamics of chemical-electrical signaling during specific neural computations remain poorly understood.

To this end, here we put forward retinal ON-OFF directionally selective ganglion cells (DSGCs) as a model system for study-

\footnotetext{
Received Feb. 21, 2013; revised Aug. 8, 2013; accepted Aug. 13, 2013.

Author contributions: S.T., D.J.S., and G.B.A. designed research; S.T. and A.J.M. performed research; S.T. and A.J.M. analyzed data; S.T. and G.B.A. wrote the paper.

We thank Drs. Shigang He, Rob Smith, and Kerry Delaney for useful discussions; Kyle Johnson for programming analysis routines in MATLAB; and Alex Hoggarth and Drew Bowie for maintaining and genotyping mouse lines.

The authors declare no competing financial interests.

Correspondence should be addressed to Dr. Gautam B. Awatramani, Biology Department, University of Victoria, Victoria, BC V8W 3N5, Canada. E-mail: gautam@uvic.ca.

DOI:10.1523/JNEUROSCI.0808-13.2013

Copyright $\odot 2013$ the authors $\quad 0270-6474 / 13 / 3314927-12 \$ 15.00 / 0$
}

ing interactions between electrical and chemical synapses. ON-OFF DSGCs consist of four subtypes, each preferentially responding to stimuli moving in orthogonal directions (Oyster and Barlow, 1967) through well defined chemical synaptic interactions (Borst and Euler, 2011; Vaney et al., 2012). Interestingly, only a subset of ON-OFF DSGCs is electrically coupled (Vaney, 1994; Weng et al., 2005). Previously, based on electrophysiological measurements and pharmacology, we postulated that the superior coding DSGC population labeled in the Hb9::eGFP transgenic mouse retina corresponds to the electrically coupled population (Trenholm et al., 2013). Here, we confirm the presence of gap junctions using tracer-coupling methods and by analyzing depolarization-induced feedback spikelets in voltageclamped DSGCs. Thus, the Hb9::eGFP mouse retina presents a unique opportunity for studying roles of gap junctions during specific neural computations.

A remarkable property of superior coding ON-OFF DSGCs that arises from the combination of electrical and chemical synaptic signaling is the ability to normalize spatial lags that arise from transmission delays (i.e., these cells can detect moving edges at a constant retinal location regardless of stimulus velocity; Trenholm et al., 2013). Interestingly, the responses of coupled DSGCs were highly skewed toward the leading edge of the moving stimulus, indicating that gap junction signals from upstream DSGCs effectively primed responses (Trenholm et al., 2013). In contrast, the falling phase of the response did not appear to be 
boosted, suggesting that gap junction signals from downstream DSGCs were less effective. As gap junctions between DSGCs are thought to be composed of connexin 45 (Schubert et al., 2005; Pan et al., 2010), which exhibits a strong voltage dependence in its gating characteristics (Moreno et al., 1995; Barrio et al., 1997), one possibility was that the gap junction conductance itself was dynamically modulated as stimuli crossed the receptive fields of coupled DSGCs. Alternatively, other factors such as delayed GABAergic inhibition or changes in intrinsic properties could dynamically tune the functional efficacy of lateral excitatory gap junction signals and produce skewed responses.

Here we characterize the physiological properties of gap junctions between superior coding DSGCs and explore how they shape receptive field structure. We examine the interactions between gap junctions, chemical synapses, and the intrinsic properties of DSGCs, and demonstrate how lateral signals functionally rectify as they spread through the coupled network during stimulus motion.

\section{Materials and Methods}

Whole-mount retinal preparation. All procedures were performed in accordance with the Canadian Council on Animal Care and approved by the University of Victoria Animal Care Committee. Experiments were performed in adult wt (C57BL/6) or Hb9::eGFP transgenic mice (Trenholm et al., 2011) of either sex that were maintained on a $12 \mathrm{~h}$ light/dark cycle. In brief, mice were dark adapted for 30-60 min before being anesthetized and decapitated. During the removal of the eyes, the dorsal side of the retina was marked with a small cut to keep track of orientation. After removal of the eyes, the retina was dissected in Ringer's solution under infrared (IR) light and mounted on a $0.22 \mathrm{~mm}$ membrane filter (Millipore) with a precut window through which light was able to reach the retina, enabling the preparation to be viewed under IR illumination using a Spot RT3 CCD camera (Diagnostic Instruments) attached to an upright Olympus BX51 WI fluorescent microscope equipped with a $40 \times$ water-immersion lens (Olympus Canada). The retinal preparation was continually perfused with $35-37^{\circ} \mathrm{C}$ Ringer's solution containing the following (in mM): $110 \mathrm{NaCl}, 2.5 \mathrm{KCl}, 1 \mathrm{CaCl}_{2}, 1.6 \mathrm{MgCl}_{2}, 10$ dextrose, and $22 \mathrm{NaHCO}_{3}$ that was bubbled with carbogen $\left(95 \% \mathrm{O}_{2}, 5 \% \mathrm{CO}_{2}\right)$, pH 7.4. All reagents were purchased form Sigma-Aldrich Canada Ltd. unless otherwise noted.

Physiological recordings. Extracellular recordings were made in loose cell-attached patch-clamp mode using 5-10 $\mathrm{M} \Omega$ electrodes filled with Ringer's solution. Voltage-clamp whole-cell recordings were made using 4-7 $\mathrm{M} \Omega$ electrodes containing the following (in $\mathrm{mm}$ ): $112.5 \mathrm{CH}_{3} \mathrm{CsO}_{3} \mathrm{~S}$, $1 \mathrm{MgSO}_{4}, 10$ EGTA, 10 HEPES, 4 ATP-Mg $2,0.5$ GTP-Na 3 , 5 QX-314, 0.025 Alexa Fluor 594 (Invitrogen), and 7.75 Neurobiotin-Cl (Vector Laboratories). The $\mathrm{pH}$ was adjusted to $7.2-7.3$ with $\mathrm{CsOH}$. The reversal potential for GABA was estimated from the reversal of spontaneous events to be approximately $-60 \mathrm{mV}$. For current-clamp experiments, electrodes contained the following (in $\mathrm{mM}$ ): $115 \mathrm{~K}^{+}$gluconate, $9.7 \mathrm{KCl}, 1$ $\mathrm{MgCl}_{2}, 0.5 \mathrm{CaCl}_{2}, 1.5$ EGTA, 10 HEPES, 4 ATP- $\mathrm{Mg}_{2}, 0.5$ GTP-Na, 0.025 Alexa Fluor 594, and 7.75 Neurobiotin. The $\mathrm{pH}$ was adjusted to 7.2-7.3 with $\mathrm{KOH}$. Recordings were made with a MultiClamp 700B amplifier (Molecular Devices). Signals were digitized at $10 \mathrm{kHz}$ (PCI-6036E acquisition board, National Instruments) and acquired using custom software written in LabVIEW. GFP ${ }^{+}$ganglion cells were visually targeted for recordings using two-photon laser scanning microscopy techniques with the wavelength at $950 \mathrm{~nm}$ to minimize photoreceptor bleaching. GFP DSGCs were identified by their soma size and directionally selective response properties.

Light stimulus. Light stimuli were generated with a digital projector (refresh rate $75 \mathrm{~Hz}$; Cpx1, Hitachi) and controlled with custom software incorporating Psychtoolbox (Brainard, 1997). The ambient background intensity, as measured with a calibrated spectrophotometer (USB2000, Ocean Optics) was $3 \times 10^{12}$ photons $\mathrm{s}^{-1} \mathrm{~cm}^{-2}$ (sampled at $500 \mathrm{~nm}$ ). Retinas were light adapted for $30 \mathrm{~min}$ after dissection before recordings were made in an attempt to increase ganglion cell coupling (Hu et al.,
2010). Light stimuli were projected from below the preparation and focused on the photoreceptor outer segments using the substage condenser. The preferred (Pref) direction for DSGCs was calculated by computing a vector sum of the peak spike rates after presenting a $300 \times$ $300 \mu \mathrm{m}$ (96\% positive Weber contrast $=$ difference in luminance between foreground and background/average background luminance) stimuli moving at $600 \mu \mathrm{m} / \mathrm{s}$ in eight directions over each cell. The directionally selective index (DSI) was calculated from the peak spike rates as follows: (Pref - Null)/(Pref + Null).

Data analysis. Receptive field size was calculated by measuring the area over which a $40 \mu \mathrm{m}$ spot (maximum contrast, flashed for $1 \mathrm{~s}$ at pseudorandom locations above the cell of interest) evoked a response. Dendritic morphologies were reconstructed from two-photon images of Alexa Fluor 594-loaded cells using ImageJ (rsbweb.nih.gov/ij/). The dendritic coverage was estimated by linking the peripheral dendritic tips and calculating the area within the convex polygon. To compare classical receptive fields to responses generated by moving stimuli, spike rates were estimated by low-pass convolution-filtering of spike trains (using a Gaussian kernel with a fixed width, $\sigma=25 \mathrm{~ms}$ ), which were then plotted as a function of the stimulus edge in space. The zero point on the abscissa indicates when the stimulus edge was at the soma of the cell of interest. For direct comparison of static and moving receptive fields, we also corrected for the expected spatial lag that occurs from fixed transmission delays during which the moving stimuli covers a certain distance. Transmission delays were estimated by measuring the latency of the response of the ganglion cell to a flashing bar $(300 \times 300 \mu \mathrm{m})$. For example, for a $60 \mathrm{~ms}$ delay (measured from the light onset to the first spike in the response) we shifted the response waveform by $36 \mu \mathrm{m}$ for stimuli moving at $600 \mu \mathrm{m} / \mathrm{s}$.

To quantify response asymmetries observed in DSGC responses to moving stimuli, we computed a skew index (SI), measured as the ratio of the distance from start-to-peak to the peak-to-end of the spiking response. SI values $>1$ indicate skew toward the start of the response; a value of 1 indicates a symmetrical response; and values $<1$ indicate skew toward the trailing edge of the response. Comparisons between groups were made with $t$ tests. Comparisons made between recordings from the same cell before and after applying pharmacological agents were made using paired $t$ tests. For data that failed normality tests, we used the Mann-Whitney rank sum test instead of $t$ tests, and we used the signed rank test instead of paired $t$ tests. Data are presented as the mean \pm SEM.

\section{Results}

\section{Reciprocal gap junction coupling in superior coding DSGCs}

In the rabbit retina, $\sim 40 \%$ of ON-OFF DSGCs are homologously tracer coupled (Vaney, 1994). However, since tracer-coupling methods have never been combined with functional analysis for different DSGC subtypes, it remains unclear whether coupling occurs within single or multiple populations of DSGCs. Here, we use a combination of tracer-coupling methods, mouse genetics and physiological recordings to determine which types of ONOFF DSGC are electrically coupled.

Previously, we demonstrated that DSGCs coding superior motion were selectively labeled in the Hb9::eGFP transgenic retina (Trenholm et al., 2011). Loading individual GFP ${ }^{+}$DSGCs in the Hb9::eGFP transgenic retina (Fig. 1A, left) with the gap junction-permeable tracer Neurobiotin not only revealed the dendritic arborizations of the injected ganglion cell, but also led to robust labeling of somata of neighboring ganglion cells (Fig. $1 A$, middle). Tracer coupling was only present in other $\mathrm{GFP}^{+}$ cells (Fig. 1A, right), demonstrating that superior coding DSGCs were homologously tracer coupled. On average, GFP ${ }^{+}$DSGCs were tracer coupled to $7.4 \pm 0.7$ neighboring DSGCs $(n=5 / 5)$, though it should be noted that the intensity of labeling was not uniform in all coupled DSGCs. Additionally, we saw no evidence of heterologous tracer coupling to amacrine cells or other ganglion cell types. In contrast, Neurobiotin labeling of $\mathrm{GFP}^{-}$ 
A

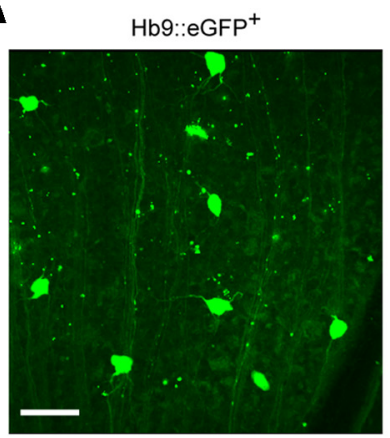

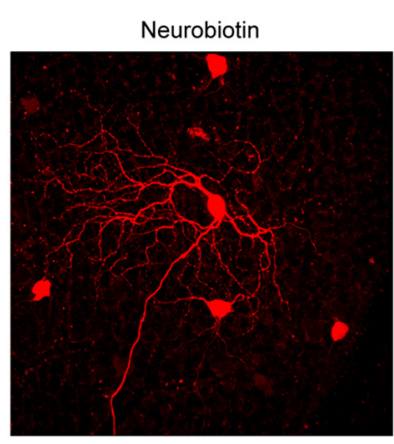

B

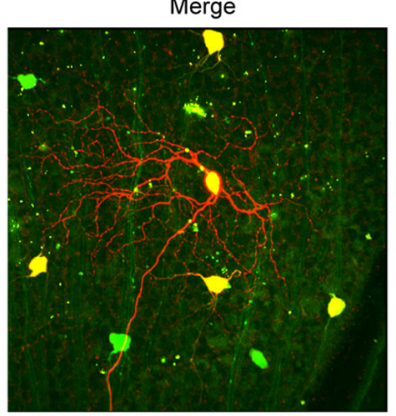

Hb9::eGFP- Neurobiotin

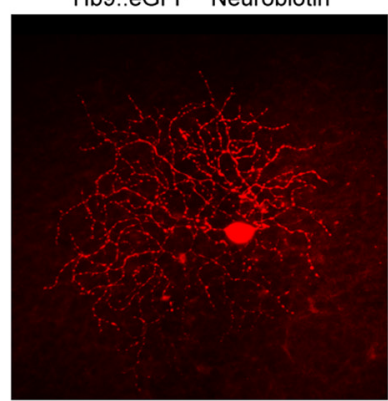

Figure 1. Superior coding Hb9::eGFP directionally selective ganglion cells are homologously tracer coupled. A, Photomicrograph illustrating the somata of GFP ${ }^{+}$DSGCS labeled in the Hb9:::eGFP mouse retina (green, left). Injection of the gap junction-permeable tracer Neurobiotin into a single DSGC revealed its dendritic morphology and also labeled several neighboring somata (red, middle). Overlaying the red and green channels (right) revealed that Neurobiotin spread exclusively to other GFP ${ }^{+}$DSGCs, indicating that coupling is homologous. $\boldsymbol{B}$, Neurobiotin injection into an $\mathrm{Hb}^{-}$ DSGC revealed the dendritic tree of the injected cell but did not label any neighboring cells. Scale bar, $50 \mu \mathrm{m}$.

A

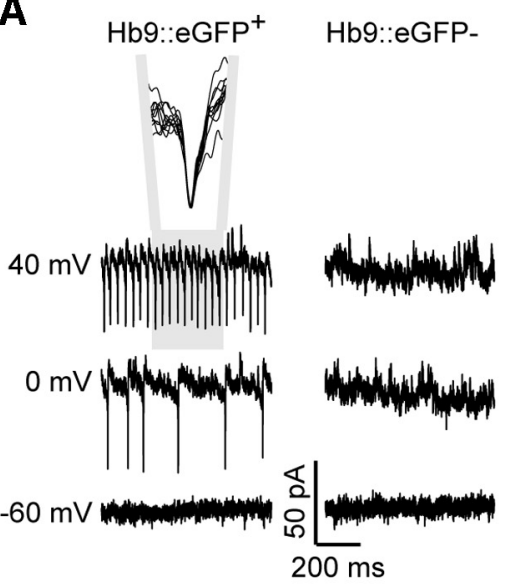

$\mathbf{E}$
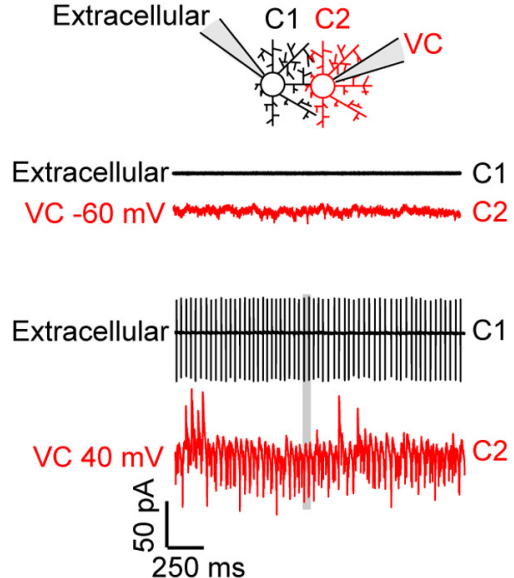

$\mathbf{F}$

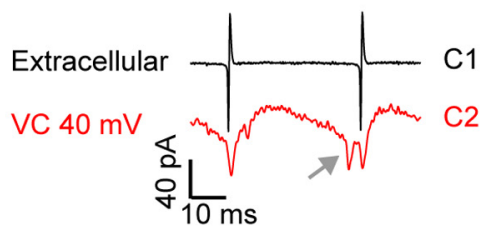

G

$\mathbf{B}$

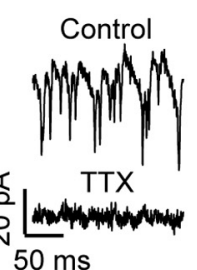

C Control
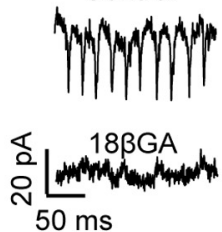

D
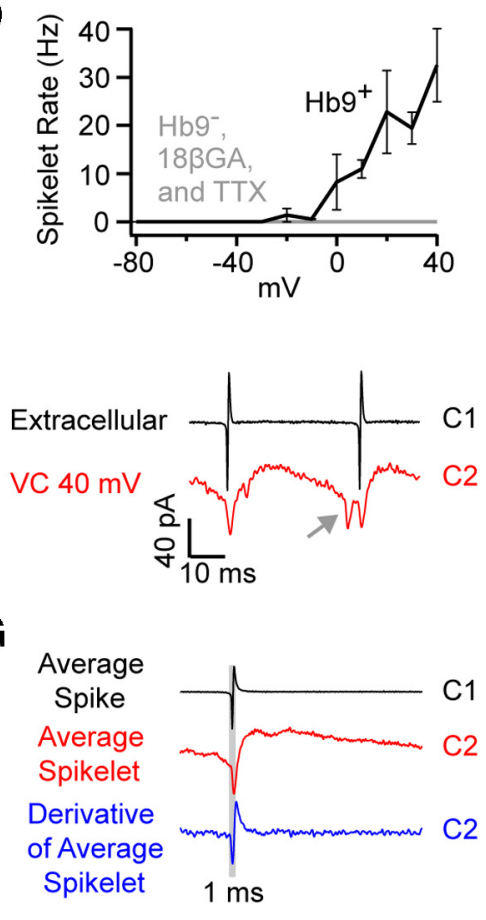

Figure 2. Superior coding $\mathrm{Hb}^{+}{ }^{+}$DSGCs exhibit coupled spikelets. $A$, Upon voltage-clamping the membrane potential above $\sim 0 \mathrm{mV}$, fast inward currents (spikelets) were observed in $\mathrm{Hb}^{+}$(left), but not $\mathrm{Hb}^{-}$(right) ON-OFF DSGCs. The inset in $\boldsymbol{A}$ shows the overlay of 10 consecutive spikelets, indicating their uniform size and waveform. $B, C$, Depolarization-induced spikelets were abolished in the presence of $1 \mu \mathrm{M}$ TTX (a voltage-gated $\mathrm{Na}^{+}$channel blocker; $\boldsymbol{B}$ ) and in the presence of $25 \mu \mathrm{m} 18 \beta \mathrm{GA}$ (gap junction blocker; application $10-20 \mathrm{~min} ; \boldsymbol{C}$ ). D, Spikelet frequency plotted as a function of holding potential. $\boldsymbol{E}$, An example of a paired recording from neighboring DSGCs, in which spike activity in $C 1$ was measured in cell-attached mode, while whole-cell voltage-clamping (VC) its neighbor (C2) near $-60 \mathrm{mV}$ (top) or $+40 \mathrm{mV}$ (bottom). $\boldsymbol{F}$, A high-resolution view of the area highlighted in gray in $\boldsymbol{E}$, showing spikelets (red) immediately follow action potentials in $C 1$ (black). The gray arrow points to a spikelet that does not correspond to an action potential in C1, which likely arose from an action potential in another DSGC that is coupled to C2. G, The average of spike waveforms in C1 (black) and C1 spike-triggered average of currents in $C 2$ (red, $V_{\text {HOLD }} \sim 0 \mathrm{mV}$ ) are plotted for the pair of cells shown in $\boldsymbol{E}$. The derivative of the average spikelet (blue) appears as a low-pass-filtered version of the spike measured in C1 (black).

ON-OFF DSGCs showed no detectable coupling to neighboring ganglion or amacrine cells $(n=7 / 7$; Fig. $1 B)$.

While Neurobiotin labeling confirms the presence of gap junction coupling between superior coding DSGCs, the absence of tracer coupling in other populations does not conclusively demonstrate that these cells were not coupled. As an alternate method, we assessed coupling in the live retinal preparation by testing the ability of DSGCs to drive reciprocal feedback spikelets. When superior coding DSGCs were voltage-clamped at depolarized potentials $(+40 \mathrm{mV})$, fast inward currents that had an average peak amplitude of $21 \pm 2 \mathrm{pA}$ were observed (Fig. $2 A ; n=6$ ). Below, we present several lines of evidence demonstrating that spikelets arise from spike activity in neighboring coupled cells, triggered as the command voltage spread through gap junctions.

First, spikelets were observed only when cells were strongly depolarized above $\sim 0$ $\mathrm{mV}$. Given that the spike threshold of a DSGC is $\sim 10 \mathrm{mV}$ above the resting potential, the requirement for strong depolarizations in the neighboring cell indicates that only a small fraction of the depolarizing current spreads into neighboring $\mathrm{Hb}^{+}$ganglion cells. Increasing the strength of depolarization led to a proportional increase in the frequency of spikelets in the voltage-clamped cell (Fig. $2 A, D ; n=6$ ). Second, consistent with a gap junction origin, spikelets did not exhibit a reversal potential and remained inward even at a holding potential $\left(\mathrm{V}_{\mathrm{HOLD}}\right)$ of $+40 \mathrm{mV}$, a potential where excitatory chemical synaptic currents are expected to be reversed (Fig. $2 A)$. Third, blocking voltage-gated $\mathrm{Na}^{+}$ channels (bath application of $1 \mu \mathrm{M}$ TTX) completely abolished spikelets (Fig. $2 B ; n=$ 4). The actions of TTX were likely mediated through blockade of action potentials in 
neighboring coupled DSGCs, since a $\mathrm{Na}^{+}$channel blocker $(5 \mathrm{~mm}$ QX-314) was included in the intracellular recording solution. Fourth, application of the gap junction blocker $18 \beta$-glycyrrhetinic acid ( $25 \mu \mathrm{M} 18 \beta \mathrm{GA}$ ) also abolished depolarization-induced spikelets (Fig. $2 C ; n=5$ ), although it did not block light-driven spiking responses in neighboring coupled cells (see Fig. 6C).

To directly confirm that spikelets arose from action potentials in neighboring coupled DSGCs, we made paired recordings from adjacent $\mathrm{Hb} 9^{+}$DSGCs and examined the temporal relationship between spikes and spikelets. In these experiments, capacitive spikes were measured in one cell in cell-attached mode, and currents were measured in a neighboring cell in voltage-clamp mode (Fig. 2E-G). When a GFP ${ }^{+}$DSGC was voltage-clamped near $-60 \mathrm{mV}$, its coupled neighbor was quiescent. However, when depolarized to $+40 \mathrm{mV}$, a train of spikes was evoked in the neighboring DSGC (Fig. $2 E ; n=10$ pairs). In turn, every action potential in the train was followed by an inward spikelet in the voltageclamped cell (Fig. $2 E, F ; n=10$ pairs). Spike-triggered events, representing the average spikelet, exhibited a uniform waveform (Fig. $2 G$; for an overlay of 10 consecutive spikelets, also see Fig. $2 A$ ). Moreover, the derivative of the average spikelet current allowed for a direct comparison of the spikelet waveform to the capacitive spike waveform (Fig. $2 F, G$ ) and revealed that spikelets peaked $0.44 \pm 0.04 \mathrm{~ms}$ ( $n=10$ pairs) after the action potential in the prejunctional cell, consistent with idea that spikelets arise from action potentials in neighboring cells. However, every spikelet in the voltage-clamped cell was not preceded by an action potential in the neighboring cell that we were recording from (Fig. $2 F$, gray arrow), suggesting that spikelets arise from multiple surrounding, coupled ganglion cells.

In summary, we have shown that depolarization-induced feedback spikelet currents arise from reciprocal coupling and provide a convenient way to determine whether DSGCs are functionally coupled in the live preparation. Interestingly, while depolarization-induced feedback spikelets were observed in every GFP ${ }^{+}$DSGC tested $(n=20 / 20)$, they were never observed in $\mathrm{GFP}^{-}$DSGCs (Fig. $2 A ; n=0 / 17$ comprising 4 inferior, 2 anterior and 11 posterior coding ON-OFF DSGCs). These findings provide further evidence that superior coding DSGCs are the only strongly functionally coupled population of ON-OFF DSGC in the adult mouse retina. For simplicity, in the rest of this article we refer to superior coding ON-OFF DSGCs as coupled and all other directions of DSGCs as uncoupled.

\section{Coupling is weak and symmetrical along the preferred-null axis}

In line with previous studies in the retina (Mastronarde, 1983; $\mathrm{Hu}$ and Bloomfield, 2003), the experiments outlined above (Fig. 2) clearly demonstrate that depolarizing a single coupled ganglion cell can effectively drive spiking activity in its coupled neighbors. However, evoking spikes in neighboring cells through gap junctions required a strong sustained depolarization $\left(\mathrm{V}_{\mathrm{HOLD}}>0 \mathrm{mV}\right)$ of the $\mathrm{Cs}^{+}$-filled DSGC (also see Vervaeke et al., 2012; for a similar requirement in cerebellar Golgi interneurons), making it questionable whether gap junction signals from individual DSGCs could drive suprathreshold activity in neighboring cells under physiological conditions. To directly test the extent to which responses in individual DSGCs drive spiking in neighboring cells under more physiological conditions, we made whole-cell current-clamp recordings (with $\mathrm{K}^{+}$-gluconate in the pipette) from pairs of coupled DSGCs and examined how modulating the membrane potential of a single cell (the donor) affected the membrane potential of its neighbor (the acceptor). Furthermore, we selected cells that were aligned along the pre- ferred-null (dorsal-ventral) axis to investigate potential directional asymmetries in gap junction signaling.

Hyperpolarizing the donor cell (current injection, $-80 \mathrm{pA}$ ) resulted in a hyperpolarization of smaller amplitude in the acceptor (Fig. 3A). As a measure of the strength of coupling, we computed a coupling coefficient (CC), defined as the fraction of the voltage deflection in the acceptor compared with that observed in the donor cell. We found that, regardless of whether the donor was on the preferred or null side, the CC was similar (preferrednull CC $=0.14 \pm 0.01 ;$ null-preferred CC $=0.13 \pm 0.01 ; p>$ $0.05 ; n=11$ pairs). Plotting the CC measured in the preferred versus the null direction for each pair resulted in values that were fit by a line with a slope of $0.94 \pm 0.07$, indicating that gap junction coupling was symmetrical (Fig. $3 B ; n=11$ pairs). Using the method for calculating gap junction conductance from paired current-clamp recordings established by Fortier and Bagna (2006), we estimate gap junctions between pairs of coupled DSGCs to have a resistance of $\sim 1 \mathrm{G} \Omega$ (i.e., $\sim 1 \mathrm{nS}$ conductance).

Next, we tested whether spiking activity in an individual coupled neuron could drive suprathreshold activity in its coupled neighbors. Injecting large currents (up to $200 \mathrm{pA}$, to mimic bipolar cell input) triggered a train of action potentials $(84 \pm 4 \mathrm{~Hz})$ riding a $13 \pm 1 \mathrm{mV}$ plateau depolarization in the injected cell but never resulted in the generation of action potentials in the acceptor cell ( $n=12$ cells from 6 pairs; Fig. 3A). Instead, each action potential was highly attenuated and manifest as a $\sim 0.5-2 \mathrm{mV}$ spikelet in the soma of the neighboring cell. Coupled spikelets appeared as low-pass filtered versions of the action potential, suggesting that action potentials passing through gap junctions do not directly activate nonlinear conductances in the dendrites of DSGCs (Oesch et al., 2005). Together, these results indicate the coupling between DSGCs is symmetrical along the preferrednull axis and that spike activity in one coupled cell results in subthreshold activity in its coupled neighbors.

To further assess the filtering properties of gap junctions between DSGCs, we injected current pulses of increasing frequencies into a donor cell and monitored the amplitude of voltage deflections in a coupled neighbor (Fig. 3C). Similar to previous findings for other neurons previously in the CNS (Bennett and Zukin, 2004; Connors and Long, 2004; Pereda et al., 2013), gap junction-mediated signals between DSGCs were low-pass filtered with a corner frequency of $\sim 10 \mathrm{~Hz}$ (Fig. 3C,D). Strong low-pass filtering is likely mediated by a combined effect of gap junction conductance, membrane resistance, and membrane capacitance.

\section{Excitatory subthreshold receptive fields of coupled DSGCs}

With an understanding of the biophysical properties of gap junctions between DSGCs, we next examined how gap junctions influenced spatial receptive fields. We first compared the size of classical receptive fields of coupled and uncoupled DSGCs in relation to their dendritic arborizations, as previously described (Yang and Masland, 1994). Classical receptive fields were defined as the area over which spot stimuli ( $40 \mu \mathrm{m}$ diameter, $96 \%$ Weber contrast) evoked spike activity. Dendritic arborizations were imaged immediately after the recordings using two-photon microscopy techniques (Fig. 4A). We observed that the average ratio of the classical receptive field to dendritic field was similar for coupled and uncoupled DSGCs for both the ON (1.38 \pm 0.09 vs $1.20 \pm 0.08$ for coupled and uncoupled DSGCs, respectively; $n=$ $11 ; p>0.05)$ and OFF $(1.34 \pm 0.07$ vs $1.13 \pm 0.05$ for coupled and uncoupled DSGCs, respectively; $n=11 ; p>0.05$ ) subdivisions. These results indicate that coupling does not significantly 
A

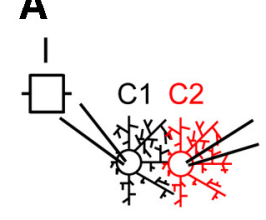

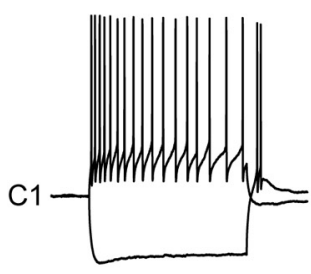

\section{要}

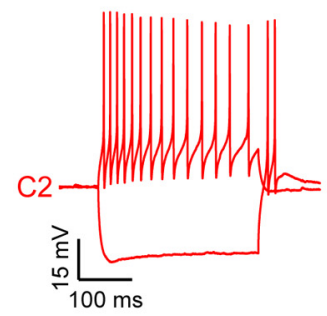

C
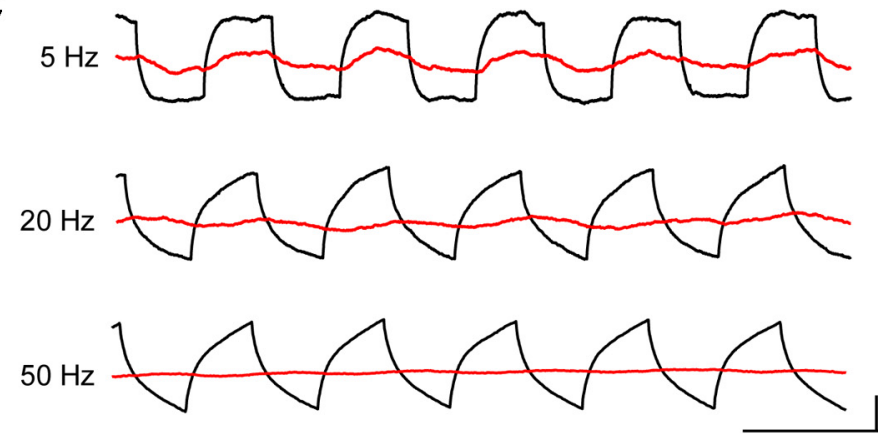

B

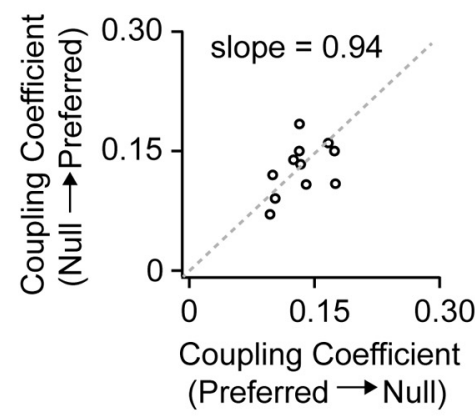

D

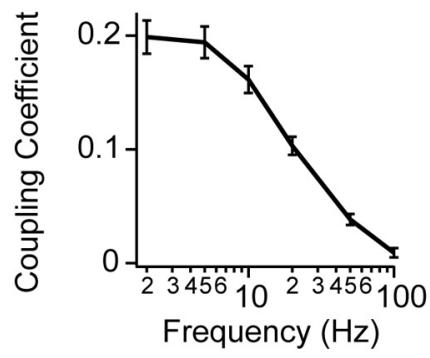

Figure 3. Coupling between ON-OFF DSGCS is reciprocal, symmetrical, and weak. $A$, Modulating the membrane potential via direct hyperpolarizing or depolarizing current injections into a DSGC $(-200$ and $+120 \mathrm{pA}$, respectively) drives weak voltage deflections in a coupled neighbor (C2; top right). Similar results are obtained when current is injected into $C 2$, indicating that coupling is reciprocal (bottom). The inset shows a magnified view of coupled spikelets (indicated by ${ }^{*}$ ), which closely follow action potentials in the prejunctional cell. $\boldsymbol{B}$, A plot of the coupling coefficient (for $D C$ injections, see text for definition) for preferred versus null directions for 11 coupled pairs. The gray dotted line represents the line of best fit, with a slope of $0.94 \pm 0.07$, indicating that coupling is symmetrical along the preferred-null axis (it should be noted that the line was forced to go through 0,0$)$. C, Current pulses of different frequencies (1-100 Hz) were injected into $\mathrm{C}(\mathrm{black}$ ), while simultaneously monitoring the membrane potential of a coupled neighbor ( $(2$, red). The horizontal time-scale bar for the different frequencies is $200 \mathrm{~ms}$ for $5 \mathrm{~Hz}, 50 \mathrm{~ms} \mathrm{for} 20 \mathrm{~Hz}$, and $20 \mathrm{~ms}$ for 50 $\mathrm{Hz}$ responses. The vertical scale bar for the different frequencies is $5 \mathrm{mV}$ for $5 \mathrm{~Hz}, 4 \mathrm{mV}$ for $20 \mathrm{~Hz}$, and $7 \mathrm{mV}$ for $50 \mathrm{~Hz}$ (the amplitude of the injected current was increased at higher frequencies to facilitate the measurement of voltage deflections in the donor). $\boldsymbol{D}$, A plot of the coupling coefficient as a function of frequency of current injection $(n=8)$, as shown in $\boldsymbol{C}$.
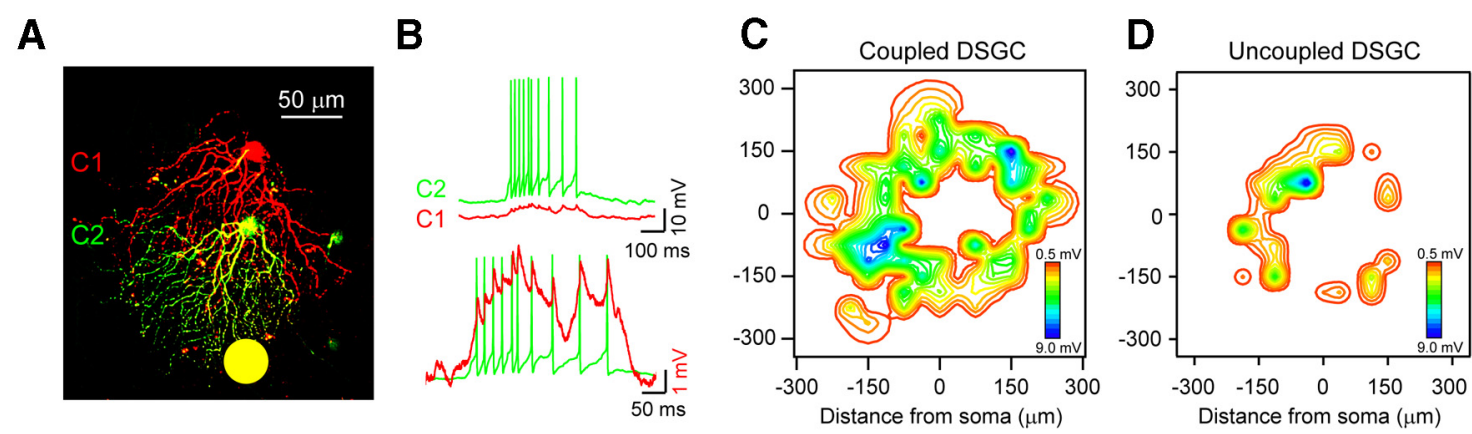

Figure 4. Coupled DSGCs have extensive excitatory subthreshold receptive fields. A, A two-photon reconstruction depicting two neighboring Hb9 ${ }^{+}$DSGCs loaded with Alexa Fluor 594 (red) and Alexa Fluor 488 (green). $\boldsymbol{B}$, The simultaneously recorded responses of C1 and C2 (top) to a spot flashed at a position indicated in $\boldsymbol{A}$ (yellow spot). The responses of C1 and C2 are normalized (bottom) to illustrate the alignment of spikes in C2 with coupled spikelet in C1. C, A contour plot of the subthreshold receptive field of a coupled DSGC (spiking responses in the center of the receptive field have been blanked). $\boldsymbol{D}$, A contour plot of the subthreshold receptive field of an uncoupled DSGC.

expand the classical receptive field, consistent with previous studies on OFF $\alpha$-ganglion cells (Hu et al., 2010).

While the size of the classical receptive field of coupled DSGCs did not appear significantly expanded, stimulating flanking regions (i.e., the surround) revealed the presence of excitatory subthreshold responses (Fig. 4B,C), rather than a classical inhibitory surround. These subthreshold responses were small in amplitude $(\sim 0.25-5 \mathrm{mV})$ and exhibited many spikelets, indicating that they were driven, at least partly, by gap junction inputs from neigh- boring cells. Indeed, simultaneous measurements from pairs of coupled cells revealed that subthreshold spikelets were aligned with the spiking response in neighboring cells (Fig. $4 A, B ; n=7$ pairs). In addition, mildly depolarizing the membrane above $\mathrm{E}_{\mathrm{Cl}}{ }^{-}$did not significantly affect excitatory subthreshold responses in the surround, indicating that these depolarizing responses were not mediated by inhibition (data not shown). The average size of the excitatory subthreshold receptive field in $\mathrm{GFP}^{+}$DSGCs was $36,183 \pm 3350 \mu \mathrm{m}^{2}(n=6$; Fig. $4 C)$, which 
A

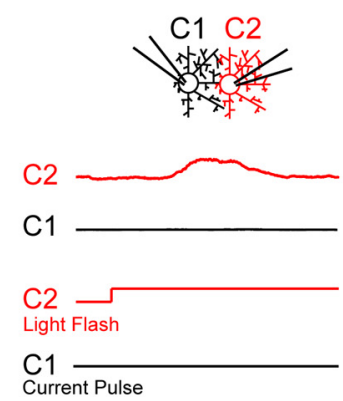

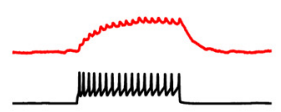

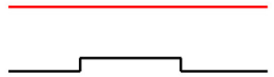

B

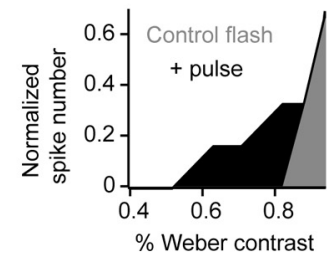

Figure 5. Lateral electrical signals boost weak light-evoked responses. $A$, A paired current-clamp recording from coupled neighboring DSGCS (C1 and C2) illustrating responses to a low contrast light flash delivered to $\mathrm{C} 2$ (left), to a $400 \mathrm{pA}$ current injected into $\mathrm{C} 1$ (middle) or to the same light flash and current injection applied in quick succession (right). The timing of the current pulse to $\mathrm{C1}$ was delayed $\sim 50 \mathrm{~ms}$ from the onset of the flash, such that it coincided with the light-evoked EPSP in C2 (the stimulus protocol is shown in the bottom panel: light, red trace; current pulse, black trace). $\boldsymbol{B}$, The normalized contrast response curve of a DSGC to spot stimuli in control conditions (gray) and when the light response was primed with coincident gap junction input mediated by depolarizing a coupled neighbor (black).

corresponds to a region extending $\sim 50-100 \mu \mathrm{m}$ around the periphery of the classical receptive field (classical receptive field diameter $\approx 200 \mu \mathrm{m}$ ). Given the average spacing of $\mathrm{Hb}^{+}$DSGCs ( $\sim 100 \mu \mathrm{m}$ apart; Trenholm et al., 2011$)$, the size of the subthreshold receptive field indicates that it arises from nearest neighbor interactions. Excitatory subthreshold receptive fields could be found on both the preferred and null sides of the classical receptive field. In contrast, uncoupled $\mathrm{GFP}^{-}$DSGCs exhibited significantly smaller subthreshold receptive fields compared with their $\mathrm{GFP}^{+}$counterparts (Fig. 4D; 17,986 $\pm 2594 \mu \mathrm{m}^{2} ; n=$ $5 ; p=0.002$ ) and never exhibited spikelets. Together, these results demonstrate that, under physiological conditions, activity in individual DSGCs (driven by small stationary spot stimuli) does not appear to be strong enough to drive suprathreshold activity in its coupled neighbors, but instead endows coupled DSGCs with large, silent excitatory surrounds.

\section{Gap junction-mediated priming of DSGC responses}

While gap junction inputs alone appeared to be ineffective in driving spike activity in neighboring cells, our previous findings suggested that coupled DSGCs could prime their neighbors by sensitizing the bipolar cell-DSGC synapse (Trenholm et al., 2013). To directly test this idea, we made paired current-clamp recordings from adjacent coupled DSGCs [cell 1 (C1) and cell 2 (C2)] and (1) stimulated subthreshold bipolar cell inputs to C2 using low-contrast light flashes (Fig. 5A, left), (2) stimulated purely gap junction-mediated responses in C2 by directly depolarizing C1 (100-150 ms pulse; 200-700 pA; Fig. 5A, middle), or (3) triggered gap junction and bipolar cell inputs in quick succession ( $\sim 50 \mathrm{~ms}$ apart) to mimic the sequential activity of DSGCs evoked by moving stimuli (Fig. $5 \mathrm{~A}$, right). When presented alone, light-driven inputs and electrical inputs gave rise to subthreshold responses in C2 (Fig. 5A, left and middle). However, when these light-driven responses were combined with subthreshold gap junction inputs, the probability of spiking was augmented (Fig. $5 \mathrm{~A}$, right). On average, gap junction input decreased the contrast required to generate a spike by $21 \pm 10 \%$ (Fig. $5 B ; n=6 ; p=0.031$ ). It is important to note that when the contrast of the spot was increased, the effect of priming by electrical synaptic input was less pronounced. These results suggest that activity in a single coupled ganglion cell can significantly affect responses in its neighbor, especially in conditions when chemical synaptic conductances are weak.

Next, to determine whether electrical priming was important during motion coding (Trenholm et al., 2013), we measured the spatial location where moving stimuli evoked spikes in relation to the classical receptive field. For simplicity, here we focused on the $\mathrm{ON}$ responses to static and moving stimuli, mediated by the ON dendrites of ON-OFF DSGCs. Classical receptive fields were mapped using static spot stimuli, and were approximated using a one-dimensional Gaussian (Fig. 6A, B; Rodieck, 1965), along the preferred-null axis. To estimate the region of retina that was associated with particular spikes stimulated during motion, we shifted responses to moving stimuli by the distance the stimulus traveled during the estimated transmission delay (see Materials and Methods). We found that for uncoupled DSGCs, the initial spikes to moving stimuli were generated at the edge of the classical receptive field (10 $\pm 5 \mu \mathrm{m}$ inside the classical receptive field; $n=7$; Fig. $6 A$ ). In contrast, coupled DSGCs responded $100 \pm 25$ $\mu \mathrm{m}$ outside of their classical receptive field (Fig. $6 B ; n=6$ ), in a region that was defined as subthreshold when mapped with stationary spot stimuli (Fig. 4). As further evidence that the initial anticipatory responses arose from priming by lateral electrical signals, blocking gap junctions with $18 \beta \mathrm{GA}$ significantly delayed the onset of spiking by $97 \pm 10 \mu \mathrm{m}(n=7$; Fig. $6 C)$, while only mildly reducing the peak firing rate ( $21 \pm 7 \%$ reduction; $n=7$ ). Thus, the sequential activation of electrical and chemical synapses by moving objects that stimulate the chain of coupled DSGCs appears to drive regions of the nominally subthreshold surround receptive field past spike threshold.

\section{Lateral priming signals are dynamically modulated during responses to moving stimuli}

Unlike the rising phase of the response to moving stimuli, the falling phase closely matched the shape of the classical receptive field for both coupled and uncoupled DSGCs (Fig. 6A, B; for both coupled and uncoupled cells, the responses to moving stimuli terminated near the end of the classical receptive field; $p=0.7$; $n=6$ coupled and 7 uncoupled DSGCs). This likely occurs due to a combination of factors including the transient nature of the light response of the DSGC, as well additional gain control mechanisms (Berry et al., 1999). Furthermore, since the initial rising phase- but not the falling phase- of responses in a coupled DSGC was primed by gap junction inputs, the overall responses to moving stimuli were significantly skewed toward the leading edge of the moving stimulus. In contrast, responses for uncoupled DSGCs were relatively symmetrical.

To characterize the skew, we plotted the relative location where responses initiated versus where they terminated, with re- 


\section{A Uncoupled DSGC}
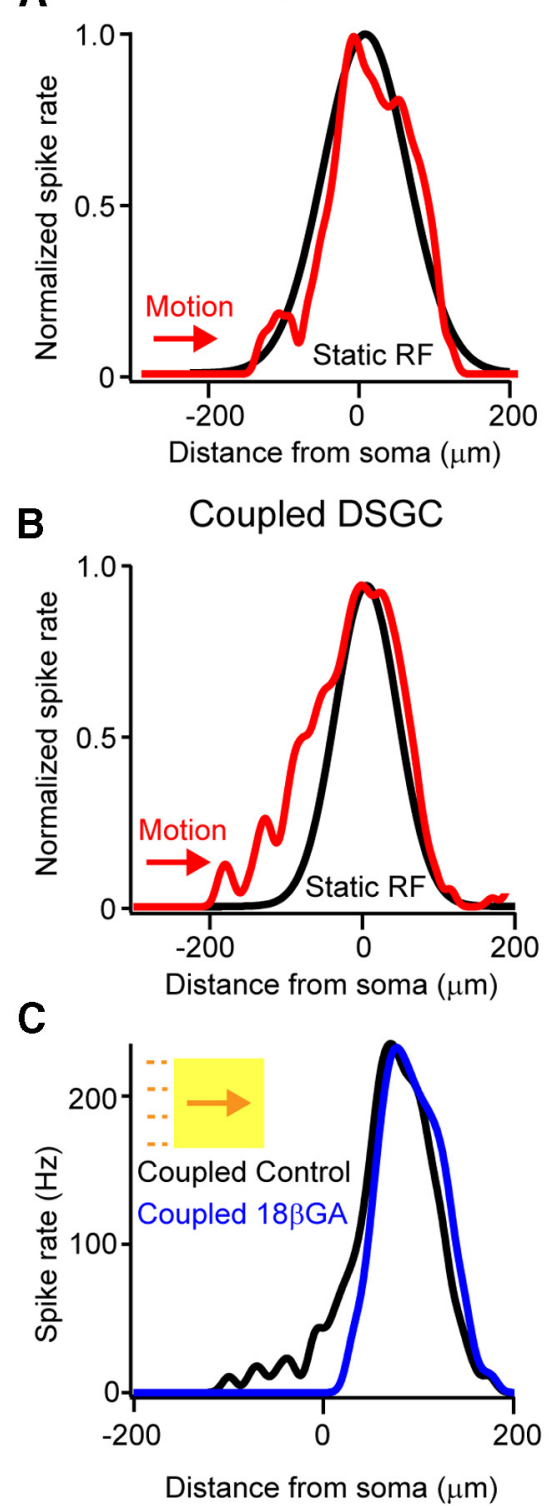
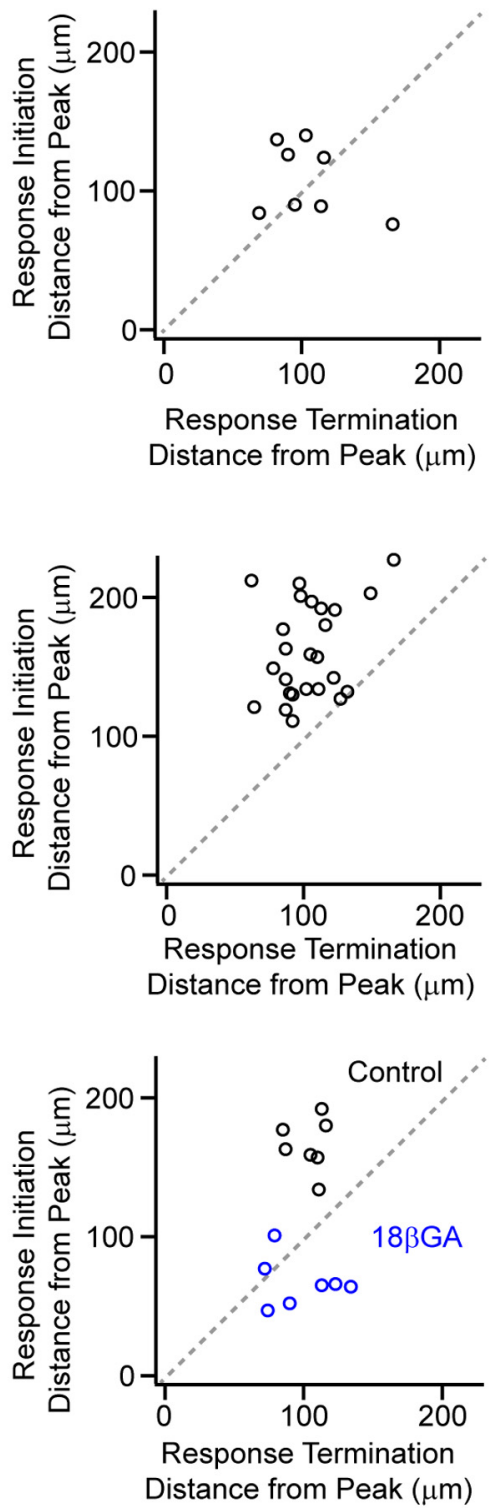

Figure 6. Moving stimuli evoke responses outside the classical receptive field of coupled DSGCS. A, B, A Gaussian approximation of the classical receptive field (mapped with a $40 \mu \mathrm{m}$ spot) for an uncoupled ( $\boldsymbol{A}$, left, black) and a coupled DSGC ( $\boldsymbol{B}$, left, black). The spiking response to a bar ( $300 \times 300 \mu \mathrm{m}$ bar; $96 \%$ Weber contrast) moving at $600 \mu \mathrm{m} / \mathrm{s}$ in the preferred direction is plotted in relation to the leading edge of the moving stimulus (the leading edge of the stimulus is at the soma at $0 \mu \mathrm{m}$; red traces). The response waveform to moving stimuli was shifted $\sim 36 \mu \mathrm{m}$ to account for the distance the edge traveled during the $\sim 60 \mathrm{~ms}$ processing delay time (see Materials and Methods). For each cell tested, the location where responses initiated is plotted against the location where responses terminated, with respect to the location of the peak spike rate $(\boldsymbol{A}, \boldsymbol{B}$, right). Values that fall on the diagonal represent symmetrical responses, whereas points that fall above the diagonal represent responses that are skewed toward the leading edge of the response. C, Application of the gap junction blocker $18 \beta \mathrm{GA}$ selectively affects the rising phase of the response of coupled DSGCs to moving stimuli. Plotting the relative location where responses initiated versus the location where responses terminated (with respect to the location of the peak rate) reveals that responses are more symmetrical in the presence of $18 \beta \mathrm{GA}$ (black vs blue).

spect to the location of the peak spike rate (Fig. $6 A-C)$. In this plot, symmetrical responses of uncoupled DSGCs clustered along the diagonal (Fig. 6A). In contrast, responses of coupled DSGCs fell above the diagonal, indicating responses were skewed toward the leading edge of the moving stimulus. An SI (the ratio of the distance from start-to-peak to the peak-to-end of the spiking response, where a value of 1 indicates a symmetrical response, and values $>1$ or $<1$ indicate skew toward or away from the leading edge of the response, respectively) was used to quantify response asymmetry to moving stimuli. For responses to bars moving at $600 \mu \mathrm{m} / \mathrm{s}$ in the preferred direction, the SI was $1.6 \pm 0.1$ for coupled DSGCs $(n=25)$ and $1.1 \pm 0.1$ for uncoupled DSGCs $(n=8 ; p=0.009)$.

Consistent with the hypothesis that electrical inputs are relatively ineffective in priming during the falling phase of the response, $18 \beta$ GA had no significant effect on the spatial location where responses terminated $(2 \pm 5 \mu \mathrm{m}$; Fig. $6 C$; $p=0.66$; $n=7)$. Since $18 \beta \mathrm{GA}$ delayed response onsets, the overall effect of blocking gap junctions was to significantly reduce response asymmetry (Fig. $6 C$; control $\mathrm{SI}=$ $1.6 \pm 0.1 ; 18 \beta \mathrm{GA}$ SI $=0.7 \pm 0.1 ; n=7$; $p=0.001)$. Together, these results indicate that moving stimuli effectively promote gap junction-mediated priming of initial near-threshold responses of coupled DSGCs, resulting in anticipatory responses. In contrast, gap junctions do not appear to boost the falling phase of the response to moving stimuli.

The question remains as to why gap junctions boost the leading but not the falling phase of the response to moving stimuli (note that both upstream and downstream coupled cells are strongly active during the rising and falling phases of the response of a given DSGC, respectively; Fig. $7 A$, gray area). These skewed responses are unexpected given the measured symmetry and non-inactivating properties of the gap junction conductance between coupled DSGCs and suggest that the dynamic modulation of priming signals that occurs during responses to moving stimuli likely occurs downstream of gap junctions.

To begin to explore the mechanism whereby gap junctions preferentially boost the rising phase of the response, we first examined the current-spike relationship of coupled DSGCs during their response to moving stimuli by making successive spike and voltage-clamp recordings from the same cells. These experiments revealed that excitatory current in the rising phase of the response was more effectively translated into spikes than current in the falling phase of the response (Fig. $7 B, C$; current at half-maximum response: during rising phase, $88 \pm 22 \mathrm{pA}$; during falling phase, $193 \pm 36 \mathrm{pA} ; n=7, p=0.029$ ). Moreover, the apparent spike threshold (i.e., the current amplitude associated with spikes) in the beginning of the spike train was significantly lower compared with that observed at the end of the response (Fig. $7 D ; n=7 ; p=0.003$ ). These results demonstrate that excitatory current is less effectively translated into spikes during the falling phase of the response to moving stimuli. Next, we tested whether the change in apparent spike threshold arises 
A

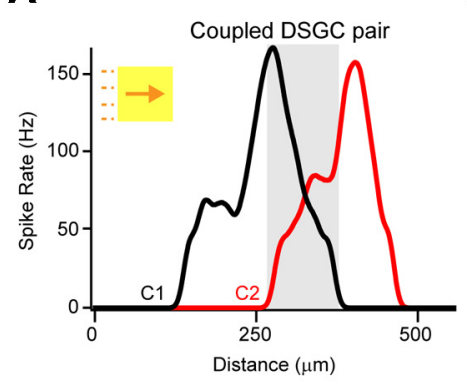

B

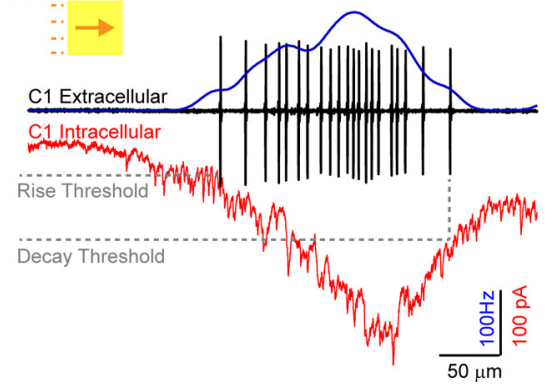

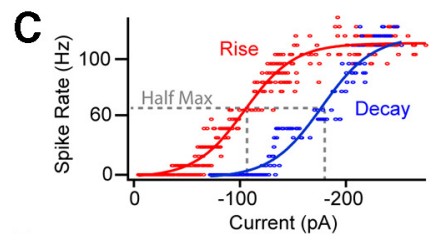

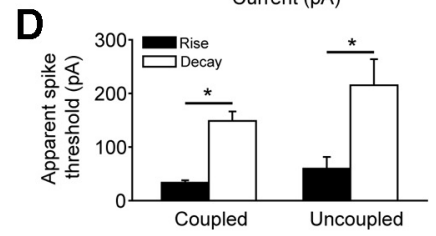

Figure 7. Gain control makes gap junctions less effective during the falling phase of the response to moving stimuli. $A$, A paired extracellular recording from neighboring coupled DSGCS reveals the window of coincident activation during the responses to moving stimuli. Note that in the overlapping region when both cells are active (highlighted in gray), $\mathrm{C} 1$ is able to prime $\mathrm{C} 2$, but $\mathrm{C} 2$ does not prime (1, giving rise to a skewed response. $\boldsymbol{B}$, The spiking ON waveform measured in a coupled DSGC (blue; raw spike traces are shown in black) is compared with its excitatory synaptic inputs (red; $V_{\text {HOLD }}$ approximately $-60 \mathrm{mV}$; these recordings were made in succession from the same DSGC). C, A plot of the spike rate versus the current for the rising (red) and decaying (blue) phases of the responses shown in $B$ reveal a dynamic change in the spike-current relationship during the light response (the current at half-maximum response during rising phase was $88 \pm 22 \mathrm{pA}$, compared with $193 \pm 36$ pA during the falling phase; $n=7, p=0.029$ ). $D$, The average apparent spike threshold (i.e., the amplitude of the synaptic EPSC at the point of the first and last spikes in the spike train) is plotted for the rising and decaying response phases of $0 \mathrm{~N}$ responses for both coupled $(n=7)$ and uncoupled $(n=6)$ DSGCs responding to a $300 \times 300 \mu \mathrm{m}$ bar ( $96 \%$ Weber contrast) moving at $600 \mu \mathrm{m} / \mathrm{s}$ in the preferred direction. ${ }^{*} p<0.05$.

from delayed GABAergic inhibition (Vaney and Taylor, 2002) or from postsynaptic adaptation (Kim and Rieke, 2003).

\section{Spatially offset inhibition does not entirely account for response skew}

DSGCs are known to receive offset GABAergic inhibition form starburst amacrine cells (Fried et al., 2002; Vaney and Taylor, 2002; Lee et al., 2010; Wei et al., 2011; Yonehara et al., 2011). Consistent with these previous findings, we found that inhibitory receptive fields of coupled DSGCs (Fig. 8C; inhibitory currents were measured in cells voltage-clamped at $\sim 0 \mathrm{mV}$ ) were offset from excitatory receptive fields (Fig. $8 B$; measured at approximately $-60 \mathrm{mV}$ ) by $52 \pm 9 \mu \mathrm{m}$ (Fig. $8 D ; n=5 ; p=0.008$ ) toward the null side of the receptive field (Fig. $8 A$ ). Thus, it might be expected that delayed inhibition could selectively shunt gap junction signals in the falling phase of the response to stimuli moving in the preferred direction and prevent these gap junction inputs from being effectively converted into spikes. To test this possibility, we next measured responses in the presence of the $\mathrm{GABA}_{\mathrm{A}}$ receptor blocker picrotoxin. As expected, blocking $G_{A B A}$ receptors significantly increased the peak spike rate (Fig. $8 E ; 198 \pm$ $14 \mathrm{~Hz}$ for control; $244 \pm 18 \mathrm{~Hz}$ in picrotoxin; $n=6$; $p=0.03$ ), but responses remained skewed toward the leading edge (SI in control $=1.6 \pm 0.2 ;$ SI in picrotoxin $=2.3 \pm 0.3 ; n=6 ; p=$ $0.031)$. Under inhibitory receptor blockade, spiking responses initiated on average $70 \pm 23 \mu \mathrm{m}$ earlier than under control conditions (Fig. $8 E, G ; n=6 ; p=0.028$ ) but terminated at nearly the same spatial location (Fig. $8 E, G ; n=6 ; 15 \pm 11 \mu \mathrm{m} ; p=0.245$ ). Thus, inhibition does not appear to be the only factor responsible for curtailing gap junction-mediated priming during the falling phase of the response of DSGCs.

In the presence of picrotoxin, null direction responses were greatly augmented (Caldwell et al., 1978), presenting the opportunity to test response skew for stimuli moving in the opposite (formerly null) direction. The peak spike rate of null direction responses increased from $27 \pm 12 \mathrm{~Hz}$ in control to $202 \pm 14 \mathrm{~Hz}$ in picrotoxin (Fig. $8 F ; n=4 ; p<0.001$ ). Interestingly, under these conditions, we observed that the downstream DSGCs, which were unable to effectively prime responses during preferred direction motion, could prime responses to stimuli moving in the opposite direction. Indeed, plotting the relative location of the response initiation versus re- sponse termination, with respect to the location of the peak spike rate, clearly demonstrates that in the presence of picrotoxin all responses to moving stimuli were skewed toward the leading edge of the moving stimulus (Fig. $8 F, G$; SI for null direction responses $=$ $3.1 \pm 0.5 ; n=4)$. Thus, regardless of the direction of the stimuli, responses were always skewed toward the leading edge of the moving stimulus, suggesting that in addition to delayed inhibition other mechanisms must contribute to the formation of skewed responses of coupled DSGCs.

\section{Postsynaptic activity affects the efficacy of gap junction signaling}

To test how postsynaptic activity might influence the effectiveness of gap junction priming in the early phase of the response, we examined the effect of preconditioning spike trains on the initial response (Fig. 9A). Preconditioning spike trains were evoked by directly depolarizing DSGCs through the patch electrode and therefore invoked only postsynaptic forms of depression. The amplitude and duration of the current injected into DSGCs (200 $\mathrm{pA}, 500 \mathrm{~ms}$ ) were chosen to produce a spike train similar to that observed during the physiological light response (peak spike rate, $85 \pm 15 \mathrm{~Hz}$; Fig. 9A). Figure $9 B$ illustrates the initial responses of DSGCs and shows that these are greatly suppressed by prior spiking activity. When the preconditioning spike trains were applied just before the leading edge of the moving stimulus reached the receptive field of the DSGC, the initial spikes in the light response were significantly decreased. To consistently compare initial responses across cells, we averaged the number of spikes observed in the first $300 \mathrm{~ms}$ of the light response and found these to be reduced by $70 \pm 6 \%(n=6)$ when the conditioning pulse terminated just before the normal onset of the light response. In contrast, the peak rate of the light response was less affected ( $40 \pm$ $10 \%$ decrease; Fig. 9B, C), and thus responses were relatively symmetrical after the conditioning train. The SI decreased from $1.71 \pm 0.35$ in control (before the train) to $1.05 \pm 0.12$ after train $(n=6 ; p<0.05)$. Moreover, the impact of the preconditioning pulse on the initial light response was transient and diminished as the time interval between the conditioning pulse and light stimulus was increased (Fig. 9D; with a recovery time constant of $604 \pm 158 \mathrm{~ms} ; n=6$ ). In summary, the finding that the initial responses were strongly attenuated by the preconditioning pulse 
A

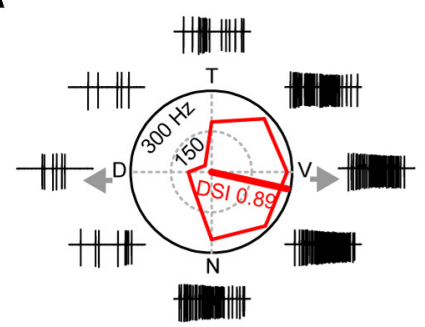

B

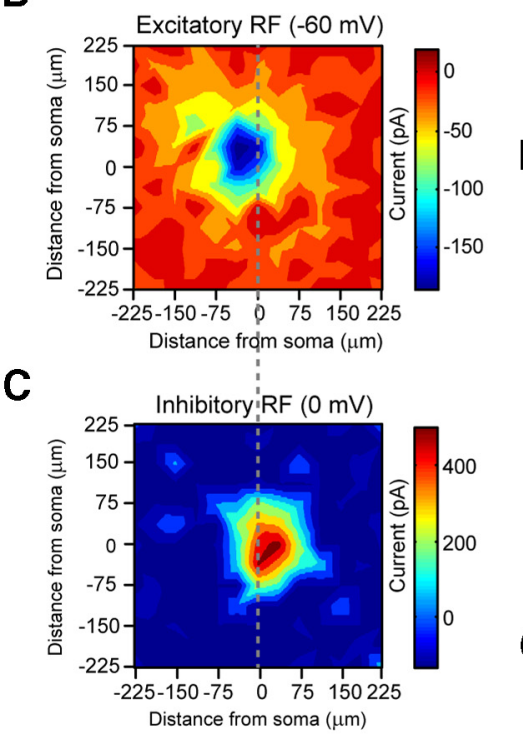

D

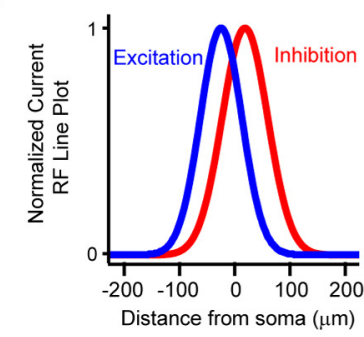

E
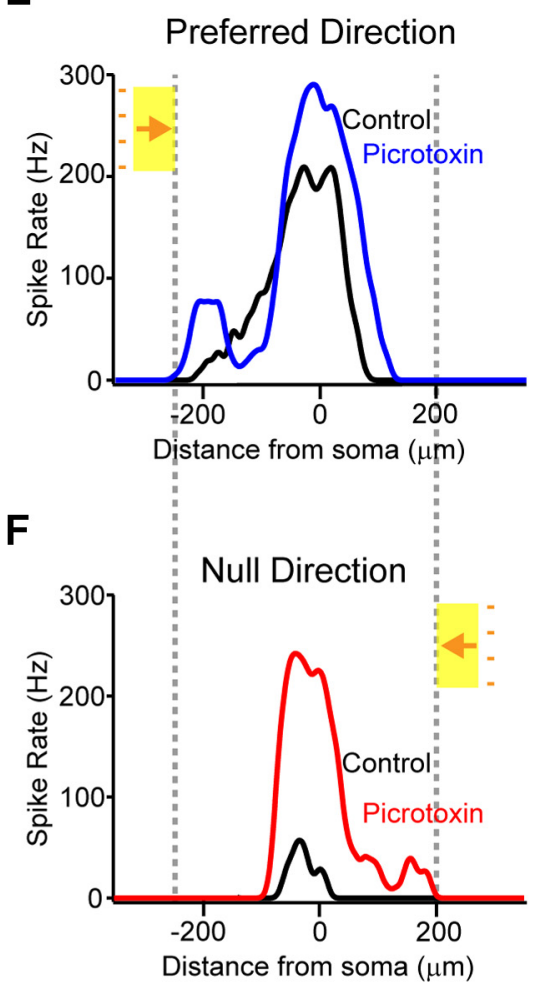

G

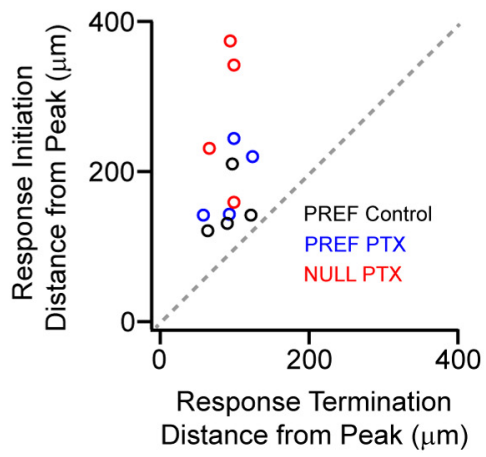

Figure 8. Inhibition is spatially offset from excitation in coupled ON-OFF DSGCS but does not completely account for skewed responses to moving stimuli.A, Peak spike rates of responses to stimuli moving in eight directions are presented in a polar plot. The raw spike traces are shown outside of the polar plot for each direction. The DSI (see Materials and Methods) is plotted as a line along the preferred direction. T, Temporal; $V$, ventral; $N$, nasal; $P$, posterior. $\boldsymbol{B}, \boldsymbol{C}$, Inhibitory $(\boldsymbol{B})$ and excitatory $(\boldsymbol{C})$ receptive fields are plotted for the $\mathrm{ON}$ responses of the same DSGC shown in $\boldsymbol{A}$. Peak current responses to small spots measured in cells voltageclamped at 0 and $-60 \mathrm{mV}$, respectively, are plotted as a function of stimulus position. $\boldsymbol{D}$, Gaussian fits of the inhibitory and excitatory receptive fields measured in $\boldsymbol{B}$ and $\boldsymbol{C}$, measured along the preferred-null axis indicate that the peaks of the excitatory and inhibitory receptive fields are offset by $52 \pm 9 \mu \mathrm{m}(n=5)$ toward the null direction. $\boldsymbol{E}, \boldsymbol{F}$, Spiking responses to the leading edge ( 0 N response) in the preferred $(\boldsymbol{E})$ and null $(\boldsymbol{F})$ directions are shown in control conditions (black) and during application of the $G_{A B A_{A}}$ receptor blocker (50 $\mu \mathrm{m}$ picrotoxin). Note that the subthreshold receptive fields are recruited only at response onsets. $\boldsymbol{G}$, Plotting the location where responses initiate versus the location where responses terminate (with respect to the location of the peak spike rate) in control conditions and in the presence of picrotoxin reveals that responses are skewed toward the leading edge of the moving stimulus, regardless of the direction of the moving stimulus.

indicates that weak inputs are susceptible to activity-dependent gain control mechanisms. Since coupled DSGCs receive a prolonged weak input via gap junctions (which initiate when upstream neighbors begin to respond to moving stimuli), their initial responses are particularly susceptible to such postsynaptic depression. These gain control mechanisms likely prevent gap junction signals from effectively generating spikes in the trailing phase of the response and promote the formation of skewed responses to moving stimuli observed in coupled DSGCs.

\section{Discussion}

Dendrodendritic electrical coupling in superior coding ON-OFF DSGCs

Here we present multiple lines of evidence that superior coding DSGCs are the only strongly coupled population of ON-OFF DSGCs in the mouse retina. First, superior coding DSGCs exhibited tracer coupling and depolarization-induced feedback spikelets, while other types of DSGCs did not. Second, superior coding DSGCs had large coupling-mediated subthreshold receptive fields that were absent from other DSGC types. Third, $\mathrm{Hb}^{+}$cells appear to be the only ON-OFF DSGC population with the ability to lag normalize (Trenholm et al., 2013).

While the finding that only one type of ON-OFF DSGC population is coupled is consistent with studies in the rabbit retina (Vaney, 1994), it appears to be at odds with previous tracer-coupling studies in the mouse retina that found bistratified ganglion cells (classified as G16 and G17) to be consistently homologously coupled (Völgyi et al., 2009; Pan et al., 2010). Another study using a genetic targeted approach in which DSGCs were identified based on their selective expression of connexin 45 also reported that two morphological types of ON-OFF DSGCs were electrically coupled (Schubert et al., 2005). While a systematic analysis of genetically identified cells in transgenic mouse lines will be required to ascertain whether weak coupling that is only detected by tracer analysis, and not feedback spikelet analysis (Fig. 2), is present between other types of ON-OFF DSGCs, our study clearly demonstrates that strong functional coupling is present only within the superior coding DSGCs.

Ganglion cells could be coupled at their axons and/or dendrites (Hidaka et al., 2004), and neither tracer-coupling methods nor examination of reciprocal feedback spikelets definitively distinguish between these possibilities. However, we found that in some cases DSGCs remained well coupled even after an axon was unintentionally severed (data not shown), indicating that coupling must occur in the dendrites (note, the soma and dendrites of DSGCs are in different layers in the inner retina and thus cannot form dendrosomatic connections). These recordings confirm that spikelets reflect spikes originating in neighboring ganglion cells that are conveyed through dendrodendritic gap junctions and establish the Hb9::eGFP retina as an ideal model system for studying the role of dendritic gap junctions in neural computations.

\section{Composite receptive field structures of coupled DSGCs}

Although it has long been recognized that many ganglion cells in the mammalian retina are electrically coupled to other ganglion 
and/or inhibitory amacrine cells (for review, see Völgyi et al., 2009), the impact of such coupling on receptive field structure has not been considered significant because the classical receptive field tends to closely match the dendritic field of coupled ganglion cells (Yang and Masland, 1994; Hu et al., 2010). However, here using whole-cell patch-clamp recordings we observed that coupling gives rise to an extensive subthreshold receptive field that surrounds the classical receptive field. As the somata of coupled DSGCs are spaced $\sim 100 \mu \mathrm{m}$ apart and the average strength of coupling is similar in all directions, the subthreshold receptive field often forms a fairly uniform ring around the classical receptive field. Such subthreshold components are likely to have been overlooked in previous studies that exclusively used spike measurements to map ganglion cell receptive fields. While coupling-mediated subthreshold receptive fields are weak when probed with small spots, they become important in the context of moving edges that sequentially activate the population of coupled ganglion cells. Such recruitment of subthreshold receptive fields during motion stimuli has also been observed in higher centers of the visual system (Grinvald et al., 1994; Hirsch et al., 1998; Bringuier et al., 1999; Jancke et al., 2004), where long-range horizontal connections spread waves of subthreshold activity and prime neurons responding to approaching stimuli.

Classic work (Barlow, 1953; Kuffler, 1953) showed that receptive fields of retinal ganglion cells, mapped with small spots of light, typically consist of an excitatory center and a concentric antagonistic surround, often modeled as a difference of Gaussians (Rodieck, 1965). The addition of excitatory signals from neighboring cells mediated by gap junction signals make this picture more complex and need to be considered in modeling responses of ganglion cells based on their spatiotemporal receptive field properties measured extracellularly (Pillow et al., 2008).

\section{Priming by gap junction-mediated lateral excitation}

Our results indicate that gap junctions play an important role in determining the precise timing of the response onsets of coupled DSGCs. Controlling the timing of the initial spikes is especially important as these may provide the brain with information about the appearance of novel stimuli (Gollisch and Meister, 2008). The activation of individual DSGCs alone, however, does not appear to directly trigger spiking in coupled neighbors under physiological conditions. By independently stimulating electrical and chemical inputs, we demonstrated that gap junction-mediated inputs bring cells closer to threshold, thus boosting weak lightdriven chemical synaptic inputs (Fig. 5; it should be noted that

A

B response
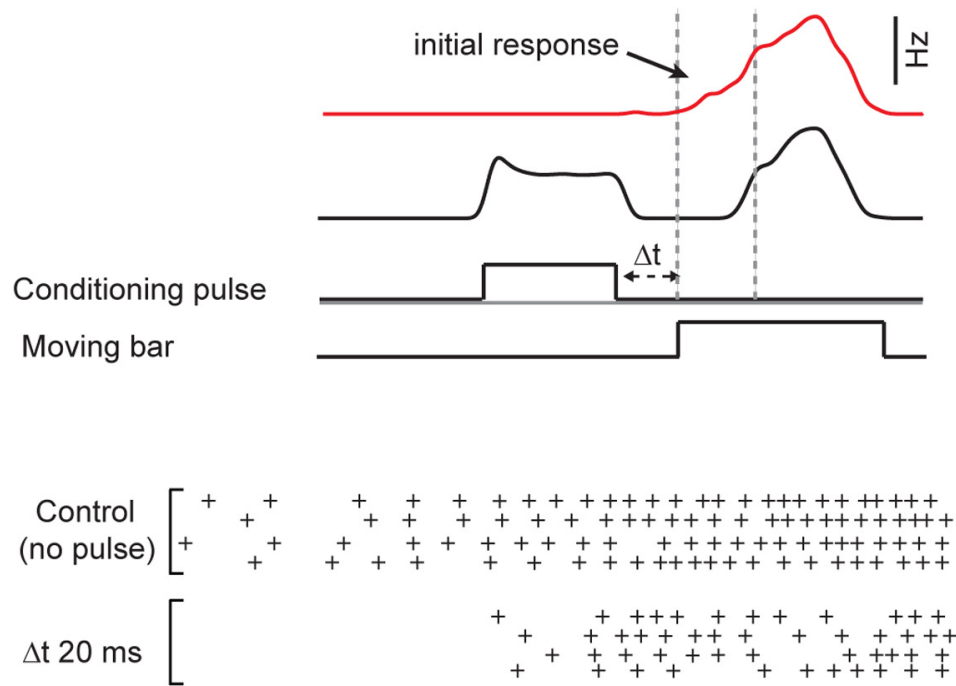

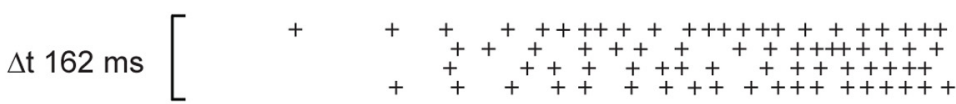

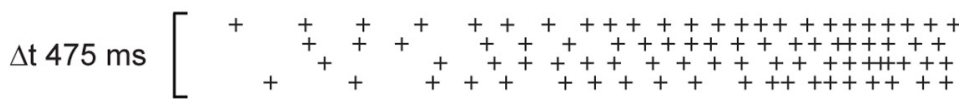

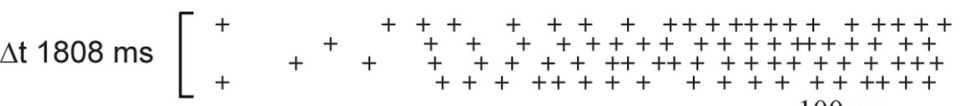

$100 \mathrm{~ms}$
C

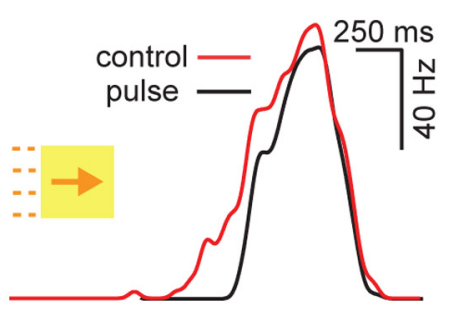

D

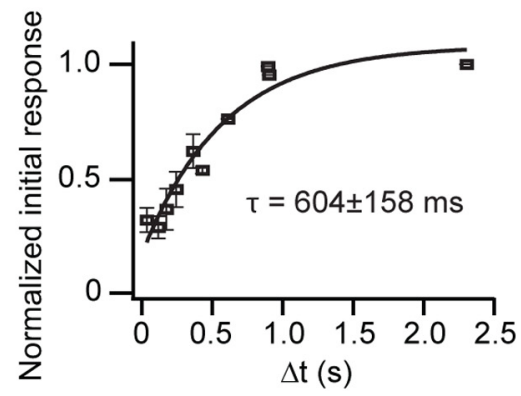

Figure 9. Postsynaptic spike activity modifies the initial gap junction-mediated responses of DSGCs. $\boldsymbol{A}$, Representative traces depicting the spiking responses (plotted as spike rate) of a coupled DSGC to moving bars of light before (red) and after (black) a preconditioning spike train was evoked by a pulse (200 pA, $500 \mathrm{~ms}$ ) applied through the patch electrode. In subsequent experiments, conditioning spike trains were evoked at various time intervals $(\Delta t)$ before the onset of the light response (bottom), as shown in $\boldsymbol{B}$ and $\boldsymbol{D}$. $\boldsymbol{B}$, Raster plots, indicating the spikes measured in a coupled DSGC, illustrating the effect of prepulses on the initial portion of light response (four trials are shown for each condition). The interval between prepulse offset and light response onset is indicated on the left. $\boldsymbol{C}$, Example traces of responses before and after a pulse are overlaid, showing that the rising phase of the spiking response is more strongly affected than the peak response. $\boldsymbol{D}$, A plot illustrating the slow recovery of the initial light response (quantified as the number of spikes in the first $300 \mathrm{~ms}$ of the light response) after prepulse conditioning. $\tau$, Recovery time

while our study emphasizes coincident activity between chemical and electrical synapses, it does not preclude a role for simultaneous gap junction input from multiple neighboring ganglion cells). Coincident chemical synaptic activity appears to be a requirement for gap junctions to exert an appreciable effect on the spiking responses of ganglion cells. The sequential activation of closely spaced DSGCs $\left(\sim 80\right.$ cells $/ \mathrm{mm}^{2}$; Trenholm et al., 2011) allows for a long window, during which electrical and chemical synapses can interact. Together, these requirements allow gap junction signals to spread in a controlled manner. While this study highlights the global interactions that occur between elec- 
trical and chemical synaptic signals, in a recent elegant study using two-photon glutamate uncaging methods, gap junctions were found to promote the local spread of excitatory charge between coupled dendrites and to help counteract the sublinear integration of chemical synaptic inputs by dendrites of inhibitory Golgi interneurons in the cerebellar cortex (Vervaeke et al., 2012). The impact of local interactions in the active dendrites of DSGCs (Oesch et al., 2005) need to be addressed in future investigations.

\section{Functional rectification of lateral excitatory signals in coupled DSGCs}

The apparent rectification of gap junction inputs during the response of coupled DSGCs to moving stimuli could result from multiple factors, including gap junction rectification or voltage inactivation, chemical synaptic inhibition, or postsynaptic adaptation. To date, rectification of electrical synapses (i.e., the finding that positive current preferentially flows in one direction) has been observed mostly in invertebrate species including crayfish (Furshpan and Potter, 1959), leech (Baylor and Nicholls, 1969; Nicholls and Purves, 1970), and lobster (Johnson et al., 1993). However, our paired current-clamp experiments revealed no direct rectification of electrical synapses between DSGCs, and the coupling coefficient was similar whether signals flowed in the preferred or null directions, similar to findings for coupled neurons throughout most vertebrate nervous systems (Bennett and Zukin, 2004; Connors and Long, 2004). Interestingly, connexin 45-mediated gap junctions- the connexins that appear to be expressed by ON-OFF DSGCs (Schubert et al., 2005; Pan et al., 2010) — are among the most voltage-dependent gap junctions, at least when examined in expression systems (Veenstra et al., 1994; Moreno et al., 1995; Barrio et al., 1997). However, sustained hyperpolarizations and depolarizations showed no voltagedependent inactivation upon passing through gap junctions. Results from these experiments suggest that it is unlikely that connexin 45 strongly contributes to functional coupling between DSGCs and implicate other connexin subtypes, including connexin 36 (Li et al., 2008) and/or connexin 30.2 (Müller et al., 2010), in mediating gap junction signals between ON-OFF DSGCs, though it remains possible that previous measurements of connexin 45-mediated currents in expression systems do not translate to currents measured in more physiological environments. Functionally, the ability of gap junctions to carry sustained signals suggests that direct modulation of these channels during physiological light responses is unlikely. Instead, here we present evidence that activity-dependent changes in the intrinsic membrane properties effectively gate the efficacy of gap junction signals, thus creating a functional rectification of electrical signals. This allows upstream but not downstream DSGCs to provide effective signals to their neighbors when coding moving stimuli.

In the presence of a $\mathrm{GABA}_{\mathrm{A}}$ receptor antagonist, which reduced directional selectivity, functional rectification of electrical signals could be observed in response to stimuli moving in both preferred and null directions, suggesting that response asymmetry arises primarily from an activity-dependent mechanism rather than from postsynaptic inhibition or heterogeneities in cell distributions. This functional rectification appears to arise from a dynamic increase in the apparent spike threshold during the spike train. Indeed, $\mathrm{Na}^{+}$channel inactivation (Kim and Rieke, 2003) and/or a build-up of $\mathrm{Ca}^{2+}$-dependent $\mathrm{K}^{+}$conductances (Wang et al., 1998; Benison et al., 2001), as have previously described for retinal ganglion cells, could explain such a phenome- non. By performing experiments where we injected a depolarizing current pulse immediately before the onset of the light response to moving stimuli, we were able to effectively delay the light response onset, showing that a postsynaptic gain control mechanism appears to increase the apparent spike threshold during sustained activity.

\section{Conclusion}

Neural networks formed by coupled DSGCs are faced with the challenge of providing strong lateral excitatory signals without causing a large expansion of receptive fields or promoting runaway excitation (arising from feedforward excitation; Douglas et al., 1995; Beggs and Plenz, 2003). Here we demonstrate two important features that permit gap junctions to signal in an effective but limited manner: first, we posit that the effective spread of lateral gap junction-mediated excitation requires coincident activation of chemical synaptic inputs. This allows lateral excitation to spread in a limited fashion, enabling superior coding ON-OFF DSGCs to detect moving stimuli far from their dendritic fields. Second, we show that activity-dependent mechanisms gate the functional efficacy of gap junction signaling. Such refractoriness in gap junction signaling prevents electrical signals from backpropagating through the network and thus promotes the spread of priming signals along the preferred axis.

Gap junction-mediated signals allow ganglion cells to anticipate moving stimuli, implying a possible role for these cells in reflexive behavior. Indeed, superior coding DSGCs send some of their projections to the accessory optic nuclei, which is an area involved in reflexive eye movements (Kay et al., 2011). However, the question remains as to why only superior coding DSGCs are electrically coupled. Since the optic flow of objects (predators) approaching from above the mouse is downward on the retina (i.e., in the preferred direction for coupled DSGCs), one possibility is that fast gap junction signaling is involved in a survival pathway.

\section{References}

Barlow HB (1953) Summation and inhibition in the frog's retina. J Physiol 119:69-88. Medline

Barrio LC, Capel J, Jarillo JA, Castro C, Revilla A (1997) Species-specific voltage-gating properties of connexin- 45 junctions expressed in Xenopus oocytes. Biophys J 73:757-769. CrossRef Medline

Baylor DA, Nicholls JG (1969) Chemical and electrical synaptic connexions between cutaneous mechanoreceptor neurones in the central nervous system of the leech. J Physiol 203:591-609. Medline

Beggs JM, Plenz D (2003) Neuronal avalanches in neocortical circuits. J Neurosci 23:11167-11177. Medline

Benison G, Keizer J, Chalupa LM, Robinson DW (2001) Modeling temporal behavior of postnatal cat retinal ganglion cells. J Theor Biol 210:187-199. CrossRef Medline

Bennett MV, Zukin RS (2004) Electrical coupling and neuronal synchronization in the mammalian brain. Neuron 41:495-511. CrossRef Medline

Berry MJ 2nd, Brivanlou IH, Jordan TA, Meister M (1999) Anticipation of moving stimuli by the retina. Nature 398:334-338. CrossRef Medline

Borst A, Euler T (2011) Seeing things in motion: models, circuits, and mechanisms. Neuron 71:974-994. CrossRef Medline

Brainard DH (1997) The psychophysics toolbox. Spat Vis 10:433-436. CrossRef Medline

Bringuier V, Chavane F, Glaeser L, Frégnac Y (1999) Horizontal propagation of visual activity in the synaptic integration field of area 17 neurons. Science 283:695-699. CrossRef Medline

Caldwell JH, Daw NW, Wyatt HJ (1978) Effects of picrotoxin and strychnine on rabbit retinal ganglion cells: lateral interactions for cells with more complex receptive fields. J Physiol 276:277-298. Medline

Connors BW, Long MA (2004) Electrical synapses in the mammalian brain. Ann Rev Neurosci 27:393-418. CrossRef Medline

Curti S, Hoge G, Nagy JI, Pereda AE (2012) Synergy between electrical coupling and membrane properties promotes strong synchronization of neu- 
rons of the mesencephalic trigeminal nucleus. J Neurosci 32:4341-4359. CrossRef Medline

Douglas RJ, Koch C, Mahowald M, Martin KA, Suarez HH (1995) Recurrent excitation in neocortical circuits. Science 269:981-985. CrossRef Medline

Fortier PA, Bagna M (2006) Estimating conductances of dual-recorded neurons within a network of coupled cells. J Theor Biol 240:501-510. CrossRef Medline

Fried SI, Münch TA, Werblin FS (2002) Mechanisms and circuitry underlying directional selectivity in the retina. Nature 420:411-414. CrossRef Medline

Furshpan EJ, Potter DD (1959) Transmission at the giant motor synapses of the crayfish. J Physiol 145:289-325. Medline

Gollisch T, Meister M (2008) Rapid neural coding in the retina with relative spike latencies. Science 319:1108-1111. CrossRef Medline

Grinvald A, Lieke EE, Frostig RD, Hildesheim R (1994) Cortical pointspread function and long-range lateral interactions revealed by real-time optical imaging of macaque monkey primary visual cortex. J Neurosci 14:2545-2568. Medline

Haas JS, Zavala B, Landisman CE (2011) Activity-dependent long-term depression of electrical synapses. Science 334:389-393. CrossRef Medline

Hidaka S, Akahori Y, Kurosawa Y (2004) Dendrodendritic electrical synapses between mammalian retinal ganglion cells. J Neurosci 24:1055310567. CrossRef Medline

Hirsch JA, Alonso JM, Reid RC, Martinez LM (1998) Synaptic integration in striate cortical simple cells. J Neurosci 18:9517-9528. Medline

Hu EH, Bloomfield SA (2003) Gap junctional coupling underlies the short-latency spike synchrony of retinal alpha ganglion cells. J Neurosci 23:6768-6777. Medline

Hu EH, Pan F, Völgyi B, Bloomfield SA (2010) Light increases the gap junctional coupling of retinal ganglion cells. J Physiol 588:4145-4163. CrossRef Medline

Jancke D, Chavane F, Naaman S, Grinvald A (2004) Imaging cortical correlates of illusion in early visual cortex. Nature 428:423-426. CrossRef Medline

Johnson BR, Peck JH, Harris-Warrick RM (1993) Amine modulation of electrical coupling in the pyloric network of the lobster stomatogastric ganglion. J Comp Physiol A Neuroethol Sens Neural Behav Physiol 172:715-732.

Kay JN, De la Huerta I, Kim IJ, Zhang Y, Yamagata M, Chu MW, Meister M, Sanes JR (2011) Retinal ganglion cells with distinct directional preferences differ in molecular identity, structure, and central projections. J Neurosci 31:7753-7762. CrossRef Medline

Kim KJ, Rieke F (2003) Slow $\mathrm{Na}^{+}$inactivation and variance adaptation in salamander retinal ganglion cells. J Neurosci 23:1506-1516. Medline

Kothmann WW, Trexler EB, Whitaker CM, Li W, Massey SC, O’Brien J (2012) Nonsynaptic NMDA receptors mediate activity-dependent plasticity of gap junctional coupling in the AII amacrine cell network. J Neurosci 32:6747-6759. CrossRef Medline

Kuffler SW (1953) Discharge patterns and functional organization of mammalian retina. J Neurophysiol 16:37-68. Medline

Lee S, Kim K, Zhou ZJ (2010) Role of ACh-GABA cotransmission in detecting image motion and motion direction. Neuron 68:1159-1172. CrossRef Medline

Li X, Kamasawa N, Ciolofan C, Olson CO, Lu S, Davidson KG, Yasumura T, Shigemoto R, Rash JE, Nagy JI (2008) Connexin 45-containing neuronal gap junctions in rodent retina also contain connexin36 in both apposing hemiplaques, forming bihomotypic gap junctions, with scaffolding contributed by zonula occludens-1. J Neurosci 28:9769-9789. CrossRef Medline

Llinas R, Baker R, Sotelo C (1974) Electrotonic coupling between neurons in cat inferior olive. J Neurophysiol 37:560-571. Medline

Mann-Metzer P, Yarom Y (1999) Electrotonic coupling interacts with intrinsic properties to generate synchronized activity in cerebellar networks of inhibitory interneurons. J Neurosci 19:3298-3306. Medline

Mastronarde DN (1983) Interactions between ganglion cells in cat retina. J Neurophysiol 49:350-365. Medline

Moreno AP, Laing JG, Beyer EC, Spray DC (1995) Properties of gap junction channels formed of connexin 45 endogenously expressed in human hepatoma (SKHep1) cells. Am J Physiol 268:C356-C365. Medline

Müller LP, Dedek K, Janssen-Bienhold U, Meyer A, Kreuzberg MM, Lorenz S,
Willecke K, Weiler R (2010) Expression and modulation of connexin 30.2 , a novel gap junction protein in the mouse retina. Vis Neurosci 27:91-101. CrossRef Medline

Nicholls JG, Purves D (1970) Monosynaptic chemical and electrical connexions between sensory and motor cells in the central nervous system of the leech. J Physiol 209:647-667. Medline

Oesch N, Euler T, Taylor WR (2005) Direction-selective dendritic action potentials in rabbit retina. Neuron 47:739-750. CrossRef Medline

Oyster CW, Barlow HB (1967) Direction-selective units in rabbit retina: distribution of preferred directions. Science 155:841-842. CrossRef Medline

Pan F, Paul DL, Bloomfield SA, Völgyi B (2010) Connexin36 is required for gap junctional coupling of most ganglion cell subtypes in the mouse retina. J Comp Neurol 518:911-927. CrossRef Medline

Pereda AE, Curti S, Hoge G, Cachope R, Flores CE, Rash JE (2013) Gap junction-mediated electrical transmission: regulatory mechanisms and plasticity. Biochim Biophys Acta 1828:134-146. CrossRef Medline

Pillow JW, Shlens J, Paninski L, Sher A, Litke AM, Chichilnisky EJ, Simoncelli EP (2008) Spatio-temporal correlations and visual signalling in a complete neuronal population. Nature 454:995-999. CrossRef Medline

Rodieck RW (1965) Quantitative analysis of cat retinal ganglion cell response to visual stimuli. Vision Res 5:583-601. CrossRef Medline

Schubert T, Maxeiner S, Krüger O, Willecke K, Weiler R (2005) Connexin45 mediates gap junctional coupling of bistratified ganglion cells in the mouse retina. J Comp Neurol 490:29-39. CrossRef Medline

Trenholm S, Johnson K, Li X, Smith RG, Awatramani GB (2011) Parallel mechanisms encode direction in the retina. Neuron 71:683-694. CrossRef Medline

Trenholm S, Borowska J, Zhang J, Hoggarth A, Johnson K, Barnes S, Lewis TJ, Awatramani GB (2012) Intrinsic oscillatory activity arising within the electrically coupled AII amacrine-ON cone bipolar cell network is driven by voltage-gated $\mathrm{Na}+$ channels. J Physiol 590:2501-2517. CrossRef Medline

Trenholm S, Schwab DJ, Balasubramanian V, Awatramani GB (2013) Lag normalization in an electrically coupled neural network. Nat Neurosci 16:154-156. CrossRef Medline

Vaney DI (1994) Territorial organization of direction-selective ganglion cells in rabbit retina. J Neurosci 14:6301-6316. Medline

Vaney DI, Taylor WR (2002) Direction selectivity in the retina. Curr Opin Neurobiol 12:405-410. CrossRef Medline

Vaney DI, Sivyer B, Taylor WR (2012) Direction selectivity in the retina: symmetry and asymmetry in structure and function. Nat Rev Neurosci 13:194-208. Medline

Veenstra RD, Wang HZ, Beyer EC, Brink PR (1994) Selective dye and ionic permeability of gap junction channels formed by connexin45. Circ Res 75:483-490. CrossRef Medline

Vervaeke K, Lorincz A, Nusser Z, Silver RA (2012) Gap junctions compensate for sublinear dendritic integration in an inhibitory network. Science 335:1624-1628. CrossRef Medline

Völgyi B, Chheda S, Bloomfield SA (2009) Tracer coupling patterns of the ganglion cell subtypes in the mouse retina. J Comp Neurol 512:664-687. CrossRef Medline

Wang GY, Robinson DW, Chalupa LM (1998) Calcium-activated potassium conductances in retinal ganglion cells of the ferret. J Neurophysiol 79:151-158. Medline

Wei W, Hamby AM, Zhou K, Feller MB (2011) Development of asymmetric inhibition underlying direction selectivity in the retina. Nature 469:402-406. CrossRef Medline

Weng S, Sun W, He S (2005) Identification of ON-OFF direction-selective ganglion cells in the mouse retina. J Physiol 562:915-923. CrossRef Medline

Yang G, Masland RH (1994) Receptive fields and dendritic structure of directionally selective retinal ganglion cells. J Neurosci 14:5267-5280. Medline

Yonehara K, Balint K, Noda M, Nagel G, Bamberg E, Roska B (2011) Spatially asymmetric reorganization of inhibition establishes a motionsensitive circuit. Nature 469:407-410. CrossRef Medline

Zsiros V, Maccaferri G (2008) Noradrenergic modulation of electrical coupling in GABAergic networks of the hippocampus. J Neurosci 28:18041815. CrossRef Medline 